\title{
KDEL Receptor 1 Contributes to Cell Surface Association of Protein Disulfide Isomerases
}

\author{
Anne-Kathrin Bartels ${ }^{a} \quad$ Sascha Göttert ${ }^{\mathrm{a}} \quad$ Christine Desel $^{\mathrm{a}} \quad$ Miriam Schäfer $^{\mathrm{a}}$ \\ Sebastian Krossa $^{\mathrm{b}}$ Axel J. Scheidig ${ }^{\mathrm{c}} \quad$ Joachim Grötzinger ${ }^{\mathrm{a}} \quad$ Inken Lorenzen ${ }^{\mathrm{c}}$ \\ alnstitute of Biochemistry, Kiel University, Kiel, Germany, ${ }^{b}$ Department of Circulation and Medical \\ Imaging, NTNU-The Norwegian University of Science and Technology, Trondheim, Norway, 'Centre of \\ Biochemistry and Molecular Biology, Structural Biology, Kiel University, Kiel, Germany
}

\section{Key Words}

ADAM17 • Extracellular PDIs • Cell surface $・$ KDEL receptor

\begin{abstract}
Background/Aims: Endoplasmic reticulum (ER)-resident proteins with a C-terminal KDEL ERretention sequence are captured in the Golgi apparatus by KDEL receptors (KDELRs). The binding of such proteins to these receptors induces their retrograde transport. Nevertheless, some KDEL proteins, such as Protein Disulfide Isomerases (PDIs), are found at the cell surface. PDls target disulfide bridges in the extracellular domains of proteins, such as integrins or A Disintegrin And Metalloprotease 17 (ADAM17) leading to changes in the structure and function of these molecules. Integrins become activated and ADAM17 inactivated upon disulfide isomerization. The way that PDIs escape from retrograde transport and reach the plasma membrane remains far from clear. Various mechanisms might exist, depending on whether a local cell surface association or a more global secretion is required. Methods: To get a more detailed insight in the transport of PDIs to the cell surface, methods such as cell surface biotinylation, flow cytometric analysis, immunoprecipitation, fluorescence microscopy as well as labeling of cells with fluorescence labled recombinant PDIA6 was performed. Results: Here, we show that the C-terminal KDEL ER retention sequence is sufficient to prevent secretion of PDIA6 into the extracellular space but is mandatory for its association with the cell surface. The cell surface trafficking of PDIA1, PDIA3, and PDIA6 is dependent on KDELR1, which travels in a dynamic manner to the cell surface. This transport is assumed to result in PDI cell surface association, which differs from PDI inducible secretion into the extracellular space. Distinct PDIs differ in their trafficking properties. Endogenous KDELR1, detectable at the cell surface, might be involved not only in the transport of cell-surface-associated PDIs, but also in their retrieval and internalization from the extracellular space. Conclusion: Beside their ER retention motive PDIs travel to the cell surface. Here they target different proteins to render their function. To escape the ER PDIs travel via various pathways. One of them depends on the
\end{abstract}




\section{Cellular Physiology Cell Physiol Biochem 2019;52:850-868 \\ \begin{tabular}{ll|l} 
DOl: 10.33594/000000059 & $\begin{array}{l}\text { O } 2019 \text { The Author(s). Published by } \\
\text { Cell Physiol Biochem Press GmbH\&Co. KG }\end{array}$ \\
\cline { 2 - 3 }
\end{tabular} \\ Bartels et al.: Cell Surface Association of Protein Disulfide Isomerases}

KDELR1, which can transport its target to the cell surface, where it is to be expected to release its cargo in close vicinity to its target molecules. Hence, the KDEL sequence is needed for cell surface association of PDIs, such as PDIA6.

\section{Introduction}

The presence of a C-terminal KDEL sequence enables endoplasmic reticulum (ER) resident proteins to be retained within the ER. If such proteins are transported via the classical secretory pathway to the Golgi apparatus, they are recognized by KDEL receptors (KDELR). Because of the acidic conditions within the Golgi apparatus, the KDEL sequence interacts strongly with these receptors [1]. Thus, ligand binding induces the oligomerization of the KDELRs and the activation of retrograde transport to the ER involving the action of protein kinase A, Arf1, and COPI [2-6]. In the ER, the cargo of the KDELR is released as a result of the increased $\mathrm{pH}$ [1]. Four human KDELRs have been described, namely KDELR1, 2 , 3a, and $3 b$ [7-9], all of which are related to the G-protein-coupled receptors of the plasma membrane [3, 10-12]. Similar to these G-protein-coupled receptors, they activate G-proteins, which induce their retrograde transport to the ER and/or prime the anterograde transport for incoming cargo. Both pathways are induced by chaperons that travel along the secretory pathway and are captured by the KDELRs $[11,13]$. The KDELRs differ in their ligand specificity. Whereas KDELR2, 3a, and 3b preferentially bind to the HDEL sequence, KDELR1 favors the KDEL sequence [9]. Remarkably, ER-resident proteins, including chaperons, such as calreticulin, GRP78 and GRP94, and Protein Disulfide Isomerases (PDIs), such as PDIA1 (PDI), PDIA3 (Erp57), and PDIA6 (Erp5), are found on the cell surface, where they mediate various functions [14-19].

Extracellular PDIs are needed for the proper activation of integrins during coagulation [20-25], for the conversion of Major Histocompatibility Complex class I chain-related molecules (MIC) A and B to become sensitive for cell surface shedding by metalloproteases [16], for virus entry [26, 27], and for the inactivation of a metalloprotease called A Disintegrin And Metalloprotease 17 (ADAM17) [28, 29]. The action of PDIs on ADAM17 has been described in molecular detail [28]. Reduced extracellular PDIs catalyze the isomerization of CXXC motives within the extracellular part of ADAM17, resulting in a structural change in the targeted membrane proximal domain (MPD) of the protease. The MPD, together with a directly C-terminal located, highly conserved "stalk region" called Conserved ADAM seventeeN Interaction Sequence (CANDIS), functions as a molecular switch in the tightly regulated protease and is involved in dimerization, substrate recognition, membrane interaction, and phosphatidylserine (PS) binding [30-35]. The last-mentioned is translocated to the outer leaflet of the plasma membrane by various stimuli of ADAM17, which, under normal circumstances, is in a resting inactive state, but which can be activated by various stimuli such as thrombin, histamine, lipopolysaccharides, Tumor Necrosis Factor (TNF) $\alpha$, and growth factors [36, 37]. The binding of PS by the MPD of ADAM17 is thought to locate the catalytic domain close to the membrane in a region in which the cleavage sites of its substrates, such as TNF $\alpha$, interleukin- (IL-) 6R, and ligands of the Epidermal Growth Factor Receptor [38], are located [39-42]. The disulfide switch changes the structure of the MPD such that PS- and ligand-binding is impaired, and hence, the enzymatic activity is abrogated [33]. PDIs, such as PDIA1, PDIA3, and PDIA6, catalyze the disulfide switch and interact with the targeted MPD in a high nanomolar range, thereby allowing not only the specific interaction, but also the unhindered release of the substrate upon catalysis [43]. During the translocation and transmission of ADAM17 through the ER, the MPD is protected against the action of the PDIs by the ER-resident chaperon GRP78 [44]. The catalysis of the disulfide switch in ADAM17 occurs at the cell surface [29]. Nevertheless, the way that the ERresident proteins escape the ER and associate with the cell surface, despite their containing a C-terminal KDEL-retention motive, remains an open question. The work reported here 


\section{Cellular Physiology Cell Physiol Biochem 2019;52:850-868 \\ \begin{tabular}{ll|l}
\cline { 3 - 3 } and Bol: 10.33594/000000059 & $\begin{array}{l}\text { O } 2019 \text { The Author(s). Published by } \\
\text { Cell Physiol Biochem Press GmbH\&Co. KG }\end{array}$
\end{tabular} \\ Bartels et al.: Cell Surface Association of Protein Disulfide Isomerases}

shows that the KDEL sequence of PDIA6 prevents secretion in resting HEK293T cells but is mandatory for its cell surface association. This is because the transport to the cell surface of HEK293T cells is influenced by the KDELR1, but the secretion of PDIs most likely takes another route. In addition to the transport of PDIs to the cell surface, KDELR1 might also be important for the retrieval of ER-resident molecules.

\section{Materials and Methods}

Eukaryotic expression constructs of PDIA6 variants

For overexpression of PDIA6 in HEK293T cells, wild-type PDIA6 and PDIA6 without the KDEL sequence was cloned into pcDNA3.1 (Invitrogen, Germany) between NheI und NotI. The C-terminal PCtag was introduced directly in front of the KDEL sequence via the polymerase chain reaction (PCR). In the case of the C-terminal Protein C (PC)-tagged PDIA6 without the KDEL sequence (PDIA6wo), the KDEL sequence was replaced by the PC-tag. The PC-tagged variants were cloned between NheI and NotI. To obtain $\mathrm{N}$-terminal myc-tagged PDIA6 expression constructs, the mature PDIA6 and PDIA6 without KDEL-sequence was cloned into pcDNA3.1 behind the sequence of a signal peptide of IL-6R and the sequence of the myc-tag. The signal peptide and myc-tag were introduced into pcDNA3.1 between NdeI and XbaI. PDIA6 was then introduced via $\mathrm{XbaI}$ and NotI.

\section{Cultivation and transfection of HEK293T cells}

HEK293T cells were cultured in high-glucose Dulbecco's Modified Eagle's Medium (DMEM) (SigmaAldrich, Germany) with $10 \%$ (v/v) fetal calf serum (FCS), penicillin $(60 \mathrm{mg} / \mathrm{L})$, and streptomycin $(100$ $\mathrm{mg} / \mathrm{L}$ ) (Sigma-Aldrich, Germany) at $37^{\circ} \mathrm{C}$ and $5 \% \mathrm{CO}_{2}$ in a humidified incubator.

For transfection, $2.5 \times 10^{6}$ and $0.4 \times 10^{6} \mathrm{HEK} 293 \mathrm{~T}$ cells were seeded in 10-cm culture dishes or 6-well plates, respectively. After 24 hours, a solution of $8 \mu \mathrm{g}$ DNA and $20 \mu \mathrm{l}$ polyethylenimine $(1 \mathrm{mg} / \mathrm{ml}$, Polysciences, Germany) in $1 \mathrm{ml}$ DMEM or $4 \mu \mathrm{g}$ DNA and $10 \mu \mathrm{l}$ polyethylenimine in $200 \mu \mathrm{l}$ DMEM were added, respectively.

\section{Biotinylation of proteins at the cell surface}

HEK293T were transfected with the indicated constructs. The cell culture medium was removed for further analysis, and the cells were washed once with PBS at room temperature (pH 7.4) and two times with cold PBS at pH 8. For biotinylation, the cells were incubated in cold biotinylation solution $(0.25 \mathrm{mg} / \mathrm{ml}$ EZ-Link Sulfo-NHS-LC-Biotin in PBS, pH 8) for 45 minutes. The biotinylation solution was removed, and the cells were washed with stop solution (100 mM glycine in PBS, pH 8) and harvested.

Cell pellets were lysed in lysis buffer/SDS (20 mM Tris, $150 \mathrm{mM} \mathrm{NaCl}, 2 \mathrm{mM}$ EDTA, 0.5\% Triton-X-100 $(\mathrm{v} / \mathrm{v}), 0.1 \%$ SDS (w/v), 5\% (v/v) Glycerin, 5\% (w/v) BSA, complete ${ }^{\mathrm{TM}}$ protease inhibitor, $\mathrm{pH}$ 7.5) and centrifuged. The clear supernatant was incubated with streptavidin sepharose beads. After incubation, the beads were washed three times with lysis buffer/SDS and three times with lysis buffer/ $\mathrm{NaCl}$ (20 mM Tris, $500 \mathrm{mM} \mathrm{NaCl}, 2 \mathrm{mM}$ EDTA, 0.5\% (v/v) Triton-X-100, cOmplete $^{\mathrm{TM}}$ protease inhibitor, $\mathrm{pH}$ 7.5). The bound proteins were analyzed by Western blot.

\section{Precipitation of secreted PDIs from the supernatant}

For the precipitation of proteins from the cell culture medium, the cleared cell culture supernatant was divided into two halves. The corresponding antibodies were added ( $+a b)$ to one half, whereas the other half was left without any antibody as a control for unspecific binding (-ab). After incubation for 30 minutes, the antibodies were precipitated with Protein A or Protein G beads. The beads were washed five times with PBS, and the bound proteins were analyzed by Western blot. PDIA6 was detected by a rabbit $\alpha$-PDIA6 antibody (ab83456, Abcam, UK).

\section{Expression and purification of recombinant PDIA6 with and without its KDEL sequence}

The coding sequences of PDIA6 with and PDIA6 without its KDEL sequence (PDIA6wo) were cloned into pET28 (Novagen, Germany) between NdeI and NotI restriction sites. Both proteins were expressed and purified as described earlier [43]. In brief, proteins were induced by the addition of $1 \mathrm{mM}$ isopropyl $\beta$-D-1thiogalactopyranoside to E. coli BL21 incubated in lysogenic broth medium for 3 hours at $37^{\circ} \mathrm{C}$. Subsequently, 


\section{Cellular Physiology Cell Physiol Biochem 2019;52:850-868 \\ \begin{tabular}{ll|l} 
and Biochemistry & $\begin{array}{l}\text { DOl: 10.33594/000000059 } \\
\text { Published online: } 9 \text { April 2019 }\end{array}$ & $\begin{array}{l}\text { O } 2019 \text { The Author(s). Published by } \\
\text { Cell Physiol Biochem Press GmbH\&Co. KG }\end{array}$ \\
\cline { 2 - 3 }
\end{tabular} \\ Bartels et al.: Cell Surface Association of Protein Disulfide Isomerases}

the bacteria were harvested, and the soluble proteins were purified via Ni-affinity chromatography and sizeexclusion chromatography in PBS.

Fluorescence labeling of PDIA6

PDIA6 protein in PBS pH 7.4 was fluorescently labeled with a five-times molar excess of DY-490-NHSEster (Dyomics, Germany) overnight at $4{ }^{\circ} \mathrm{C}$. The mixture was then separated by using a Nap5 ${ }^{\mathrm{TM}}$ column followed by a Nap $10^{\text {TM }}$ column (GE Healthcare, Germany) to remove unbound fluorophore. The final protein concentration was determined by absorption at $280 \mathrm{~nm}$ by using a NanoDrop (peQLab Biotechnology, Germany). Labeling of PDIA6woKDEL and IL-6 protein was performed in the same manner.

\section{Labeling of HEK293T cells with fluorescence-labeled PDIA6}

Cells were seeded in 6-well plates (Sarstedt, Germany) and incubated with $0.5 \mu \mathrm{M}$ fluorescently labeled PDIA6, PDIA6wo, or IL-6 in FCS-free DMEM (Sigma-Aldrich, Germany) for 3 hours at $37^{\circ} \mathrm{C}$. To block KDEL receptors, KDEL peptide was additionally given in various concentration $(2,5$, and $10 \mu \mathrm{M})$, as was unlabeled PDIA6 protein. Subsequently, cells were washed with warm PBS at pH 7.4, harvested in cold PBS, and passed into FACS buffer (1\% (w/v) BSA in PBS pH 7.4). Flow cytometry was performed on a BD FACS Canto II (BD Biosciences, Germany) to detect protein binding. Data were analyzed with FCS express 3.0 software (BD Biosciences, Germany).

\section{Immunofluorescence microscopy}

Cells were seeded on coverslips (Sarstedt, Germany) and, after two days of incubation, were washed three times with PBS. They were then incubated with $3 \mu \mathrm{M}$ fluorescently labeled PDIA6 directly or preincubated with $20 \mu \mathrm{M}$ KDEL peptide or $10 \mu \mathrm{M}$ unlabeled PDIA6 to block KDELR binding sites, for 3 hours at $37^{\circ}$ C. To remove unbound protein, cells were washed five times with PBS. Fixation was performed with $4 \%$ (w/v) paraformaldehyde for 20 minutes at room temperature followed by three washing steps with PBS. For intracellular staining, cells were permeabilized for 5 minutes with $0.2 \%$ (v/v) Saponin (Roth, Germany) in PBS. Saponin at $0.2 \%(\mathrm{v} / \mathrm{v}$ ) was further used in every buffer for intracellular staining but was omitted for extracellular staining.

To neutralize free aldehyde groups, cells were incubated with $0.12 \%(\mathrm{w} / \mathrm{v})$ glycine in PBS for 10 minutes at room temperature. A blocking step was performed with 10\% (v/v) FCS in PBS for 1 hour at room temperature. The primary anti-PDIA3 antibody (ab13506, Abcam, UK) and Alexa Fluor 594 conjugated WGA (Thermo Fischer Scientific, USA) were diluted in blocking buffer and added to the cells in a humidified chamber for an incubation time of 1 hour at $4{ }^{\circ} \mathrm{C}$. The cells were washed five times with PBS to remove unbound antibody and afterwards incubated under the same conditions with a fluorescently labeled second antibody (AlexaFluor 594 (Thermo Fischer Scientific, USA)). The coverslips were washed four times with PBS and two times with double-distilled $\mathrm{H}_{2} \mathrm{O}$. Excess fluid was removed, and the coverslips were mounted on microscope slides (Roth, Gremany) with a mixture of Mowiol (4-88 Reagent Calbiochem, USA) and DABCO (Sigma-Aldrich, Germany) containing DAPI $(1 \mu \mathrm{g} / \mathrm{ml})$. Microscope slides were dried overnight and then examined microscopically (Olympus IX 81 microscope, cLSM FluoView 1000, ObjectiveLens UPLSAPO 60X O NA:1.35, Olympus, Japan). Images were analyzed with Fluoview FV 3000 software (Olympus Life Science, Japan).

\section{Generation of KDELR1 knock-down cells}

KDEL receptor 1 knock-down cell lines were generated by using the CRISPR/Cas9 system. The guiding RNA of the gene of interest (kdelr1) was designed by means of tools available at http://crispr.mit.edu/. The exon sequence of the KDELR1 gene was submitted to design primers for target location. The designed primers (Table 1) for the target were ordered from Sigma-Aldrich (Germany).

Table 1. Primers used in this study

\begin{tabular}{lll}
\hline Parameter & Sense & Antisense \\
\hline Primer sequence & ACCGGTGTTCACTGCCCGATATC & AACGATATCGGGCAGTGAACACC \\
\hline
\end{tabular}




\section{Cellular Physiology Cell Physiol Biochem 2019;52:850-868 \\ \begin{tabular}{ll|l} 
and Bol: 10.33594/000000059 & $\begin{array}{l}\text { O } 2019 \text { The Author(s). Published by } \\
\text { Cell Physiol Biochem Press GmbH\&Co. KG }\end{array}$ \\
\cline { 2 - 3 }
\end{tabular} \\ Bartels et al.: Cell Surface Association of Protein Disulfide Isomerases}

Primers were annealed, phosphorylated with T4 polynucleotid kinase, and cloned into the SapIdigested guideRNA expressing plasmid LeGO-Cas9-iC-puro + cgRNA_SapI [45]. HEK293T cells were transfected, and at 24 hours post-transfection, puromycin $(1 \mu \mathrm{g} / \mathrm{ml})$ was added to the cells, and after an additional 24 hours, the puromycin concentration was increased to $3 \mu \mathrm{g} / \mathrm{ml}$ in order to ensure efficient selection of the transfectants. To generate further monoclonal knock-down lines, cells were singularized in a 96-well plate. After 3 weeks, the resulting colonies were expanded and analyzed by flow cytometry.

\section{Flow cytometric analysis}

Flow cytometry was performed to determine the KDELR1 knock-down of clones 3 and 7 compared with the wild-type. The analysis of the cells was executed intracellularly and extracellularly.

To permeabilize cells for intracellular staining, cells were fixed with $4 \%(\mathrm{w} / \mathrm{v})$ paraformaldehyde in PBS for 20 minutes, followed by washing steps with PBS. Permeabilization was performed with $0.1 \%$ (v/v) Saponin in FACS buffer (1\% (w/v) BSA in PBS pH 7.4) for 15 minutes. No fixation and permeabilization was carried out for extracellular staining. Cells were incubated with the first antibody, namely anti-KDEL receptor 1 (KR-10) (ab69659, Abcam, UK), for 1 hour on ice. Following washing steps with PBS, the second antibody, namely anti-mouse APC (Dianova, Hamburg), was added to the probes and incubated for 45 minutes on ice in the dark. After being washed with PBS, the cells were examined in a BD FACS Canto II (BD Biosciences, Germany), and the data were analyzed with FCS express 3.0 software (BD Biosciences, Germany).

To analyze the amount of PDIs on the cell surface in the wild-type and KDELR1 knock-down cell lines, flow cytometry analysis was performed with the primary antibodies for PDIA1 (ab137110, Abcam, UK), PDIA3 (ab10287, Abcam, UK), and PDIA6 (PA5-13616, Thermo Fisher Scientific, Germany). As a second antibody, goat anti-rabbit IgG (H+L) bound to Alexa Fluor 488 (A11034, Fisher Scientific, Germany) was used for the three primary antibodies.

\section{Internalization studies}

Internalization studies were performed with HEK293T cells stimulated with various inhibitors: Pitstop® 2 (ab120687, Abcam, UK) was used to inhibit the clathrin-dependent pathway, and Genistein (Sigma-Aldrich, Germany) was employed to inhibit the caveolin-dependent pathway. Additionally, cells were treated with DMSO as a control and with phorbol 12-myristate 13-acetate (PMA, Sigma-Aldrich, Germany) alone or with each inhibitor.

Cells were treated with the indicated concentrations of inhibitors in FCS-free DMEM and incubated for 90 minutes: $25 \mu \mathrm{M}$ Pitstop ${ }^{\circledR}$ 2, $200 \mu \mathrm{M}$ Genistein, $100 \mathrm{nM}$ PMA. The amounts of KDELR1 and PDIs on the cell surface were analyzed via flow cytometry.

\section{Results}

The KDEL-sequence is needed for cell surface association of PDIA6

PDIA6 is one of the isomerases that are able to catalyze the disulfide switch within ADAM17 [43]. To reach its substrate at the plasma membrane, the isomerase has to escape KDELR-mediated retrograde transport. To gain first insights into the underlying mechanism, wild-type PDIA6 and PDIA6 without its KDEL sequence (PDIA6wo) were overexpressed in HEK293T cells. The expression and secretion either of non-tagged PDIA6 or of N-terminalor C-terminal-tagged PDIA6 were analyzed by Western blotting. The C-terminal PC-tag was inserted directly in front of the KDEL sequence, and the N-terminal myc-tag was inserted between the signal peptide of the IL-6R and the coding sequence of the mature isomerase (Fig. 1A and 1B). The overexpression resulted only in minor secretion of the PDIA6 variants that contained the KDEL sequence (Fig. 1C and 1D). In contrast, the deletion of KDEL sequence resulted in the release of the PDIA6 into the media (Fig. 1C and 1D). This finding was observed regardless of whether the isomerase was untagged or was $\mathrm{N}$ - or C-terminaltagged. PDIA6 has to be cell surface associated to reach its extracellular targets. Thus, its cell surface association was analyzed by cell surface biotinylation (Fig. 1E - 1G). Overexpression of PDIA6 and its tagged variants resulted in a significant increase in cell surface association. In contrast, all variants without the KDEL sequence (PDIA6wo) showed no or only a minor 


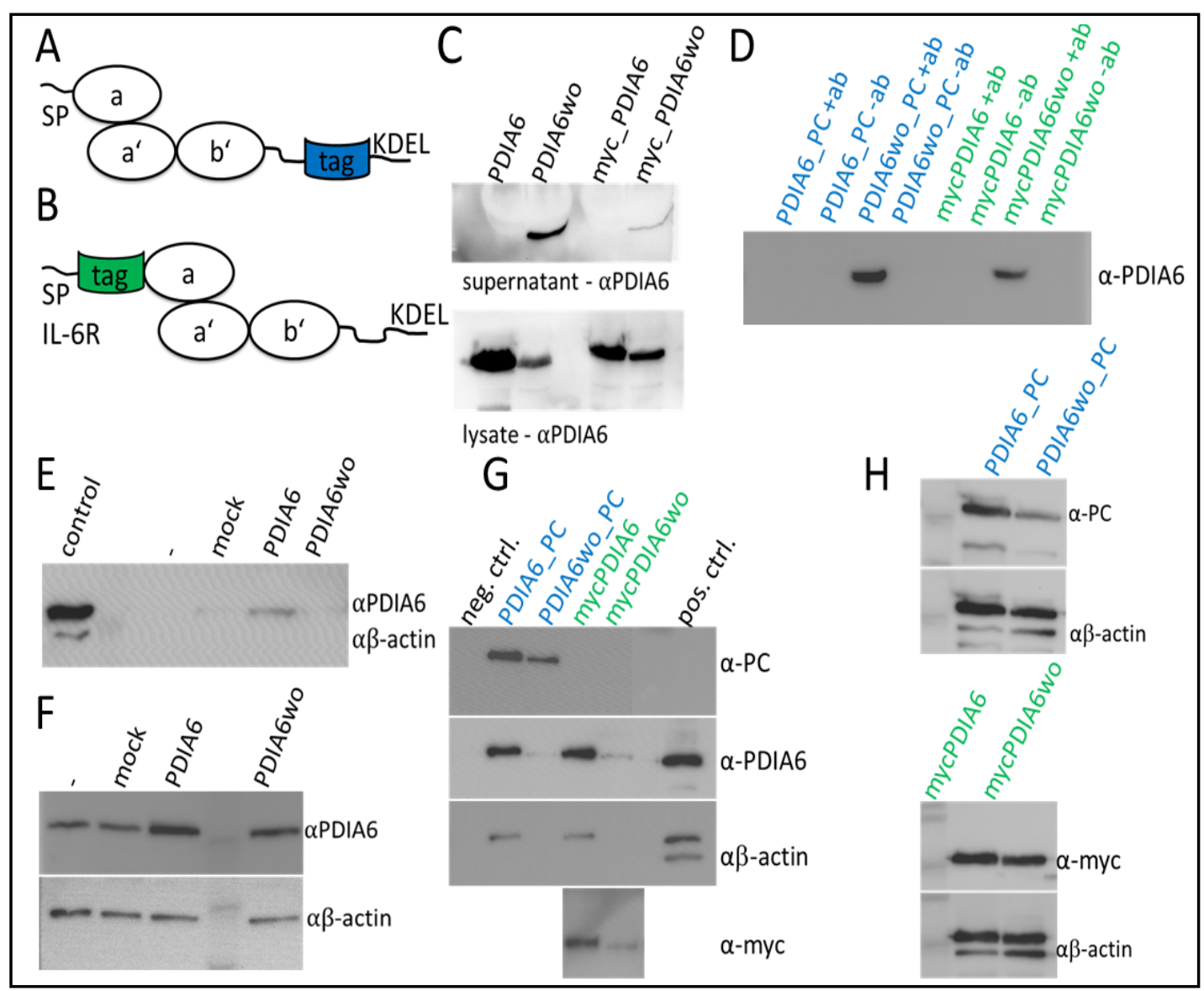

Fig. 1. The KDEL sequence of PDIA6 is mandatory for its cell surface association. (A) Schematic drawing of the C-terminal-tagged PDIA6. The PC-tag was inserted directly in front of the KDEL sequence. (B) Representation of the N-terminal myc-tagged PDIA6. The mature sequence of the isomerases was cloned directly behind the coding sequence of the signal peptide of the IL-6R followed by a myc-tag. (C) Western blot of cleared cell culture supernatant of HEK293T cells and the corresponding lysates, after overexpression of PDIA6 and PDIA6wo, either untagged or myc-tagged. In contrast to wild-type PDIA6, PDIA6wo is secreted into the supernatant. (D) This observation was verified by using either N-terminally myc-tagged or C-terminally PCtagged isomerase. After overexpression of the indicated proteins, the supernatants were harvested, cleared, and divided into two halves; Protein G beads were added to both halves, but the antibody only to one half $(+a b)$. The tagged PDIs were precipitated by using antibodies against the respective tags. In the Western blots, PDIA6 was detected by a rabbit $\alpha$-PDIA6 antibody. (E) The KDEL sequence of PDIA6 is needed for its cell surface association. PDIA6 and PDIA6wo were overexpressed in HEK293T cells. After cell surface biotinylation, the biotinylated proteins were precipitated and analyzed by Western blot with antibodies against PDIA6 and $\beta$-actin. (F) Input controls of representative cell surface biotinylation experiment shown in (E). (G) Likewise, N-terminal myc-tagged and C-terminal PC-tagged PDIA6 and PDIA6wo were overexpressed in HEK293T cells. Upon biotinylation of proteins at the cell surface, biotinylated proteins were precipitated and analyzed by Western blot by using $\alpha$-PDIA6 antibodies and myc-tag- and PC-tagspecific antibodies. As negative control function, $\beta$-actin was used, which was detected only in the control lysates. (H) Input controls of the lysates of cell surface biotinylation experiments.

increase in cell surface association. In the case of the non-tagged PDIA6wo, the amount at the cell surface was comparable with that of non-transfected cells. This indicates that the KDEL sequence is responsible for the cell surface association of PDIA6. 
PDIA6 and PDIA6wo were expressed, purified, fluorescently labeled, and incubated with HEK293T cells in order to confirm the necessity of the KDEL sequence for the interaction of PDIA6 with cells. After 30 minutes, the cells were washed and analyzed by flow cytometry. The mean fluorescence intensities of the cells incubated with PDIA6 were set to $100 \%$. Fig. 2A shows a bar diagram summarizing the results of three independent experiments. According to earlier experiments, PDIA6wo had a significant lower binding capacity to the cells compared with wild-type PDIA6 (Fig. 2A and 2B). As a negative control, human IL-6 was labeled and incubated with the cells, since HEK293T cells do not express the IL-6R and indeed showed much lower fluorescence intensity.

The necessity of the KDEL sequence for cell surface association was verified by the co-incubation of HEK293T cells with fluorescently labeled PDIA6 $(0.5 \mu \mathrm{M})$ with increasing amounts of KDEL peptide or unlabeled PDIA6 (Fig. 2C and 2D). The binding of the fluorescently labeled PDIA6 was significantly reduced in the case of co-incubation with unlabeled KDEL peptide or unlabeled PDIA6. This confirms that the KDEL sequence contributes to the cell surface association of PDIA6.

The interaction of the fluorescently labeled PDIA6 was further verified by using immunofluorescence microscopy. The plasma membranes were labeled in red with wheat germ agglutinin (WGA), and the nuclei were stained blue with DAPI. The green fluorescently labeled PDIA6 was located close to the cell surface, partially co-localized with the plasma membrane. A part of the protein seemed to be internalized, since some green dots were seen intracellularly (Fig. 3A). The staining of cells with PDIA6 was clearly reduced by coincubation with either unlabeled KDEL peptide or unlabeled PDIA6. Evidence of such successful competition strengthens the importance of the KDEL sequence for the interaction of PDIA6 with the cell surface. A co-staining with PDIA3 as a marker of the ER was performed in order to gain insight into whether the intracellular spots were localized in the ER. Since no co-localization of the red-colored ER and the green-colored recombinant PDIA6 was detectable, the retrograde transport of the protein by the KDELRs can be excluded in this setup (Fig. 3B and 3C).

\section{The transport of PDIs is influenced by KDELR1}

The impact of the KDEL sequence on cell surface association indicates the involvement of KDELRs in transport. In contrast to the other KDELRs, KDELR1 prefers the KDEL sequence over the HDEL sequence [9]. In order to establish this statement, the expression of KDELR1 was down regulated in HEK293T cells. The down regulation was identified by flow cytometry in permeabilized cells and in non-permeabilized cells (Fig. 4A-4C), because no antibodies adequately detecting the KDELR1 properly in a Western blot analysis were available. In the knock-down cell lines, the KDELR1 expression was down regulated to about $60 \%: 70 \%$ (total: extracellular) in clone 3 and about 40\%: 60\% (total: extracellular) in clone 7. The fact that only a down regulation and not a complete knock-out of the KDELR1 was achieved, despite the Crisp/CAS9 system being used, might be attributable to the HEK293T cells having multiple chromosome sets and to KDELR1 being essential for survival. Its proper function is needed for the correct folding of secreted proteins and for preventing the accumulation of misfolded protein and ER stress [46].

If the cell association of the exogenously added PDIA6 is dependent on KDELR1, then the amount of cell-bound PDIA6 should be reduced because of decreased receptor expression. Hence, fluorescently labeled PDIA6, PDIA6wo, and IL-6 were incubated with wild-type cells and the KDELR1 knock-down cell lines. For comparison, the fluorescence of the wild-type HEK293T cells incubated with PDIA6 was set to $100 \%$ cell association. Fluorescently labeled IL-6, which served as a negative control, exhibited the lowest cell binding capacity in all three cell lines (Fig. 4D and 4E). The labeled PDIA6 showed a reduced cell association in the KDELR1 knock-down cell lines compared with the wild-type cells. PDIA6wo on wild-type cells displayed a reduced cell association, which was comparable with that presented in Fig. 2A. Surprisingly, the association of PDIA6wo was further reduced on KDELR1 knock-down cells. This might be because recombinant PDIA6 exists as a dimer [43]. Hence, PDIA6wo 


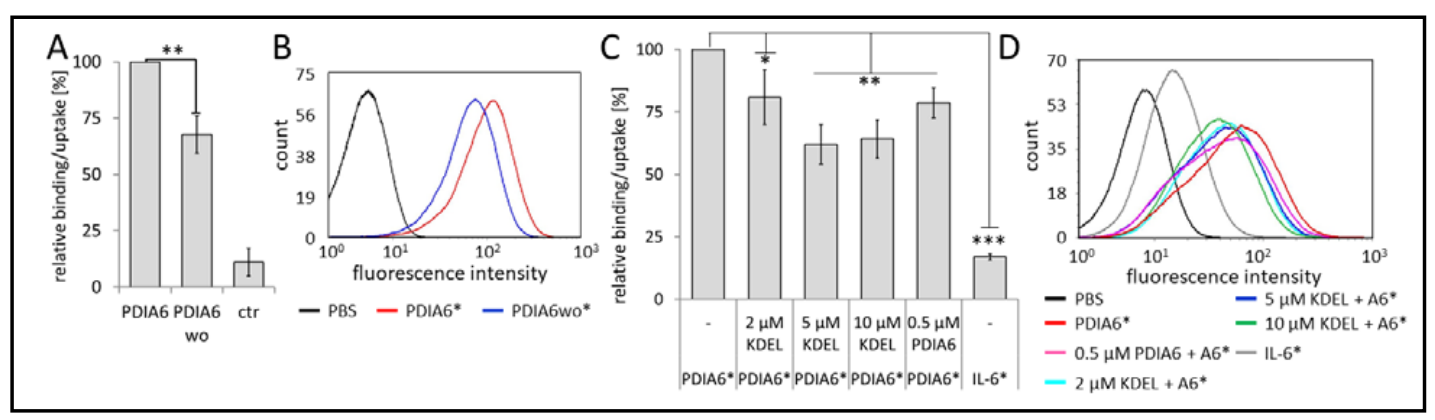

Fig. 2. Association of PDIA6 is promoted by its C-terminal KDEL sequence.(A) PDIA6 lackingits KDEL sequence shows a reduced cell surface association. PDIA6 without its KDEL sequence (PDIA6wo) and complete PDIA6 were both fluorescently labeled and, after incubation and washes, analyzed by flow cytometry. The p-value for PDIA6 compared with that for PDIA6 without its KDEL sequence (PDIA6wo) was calculated, and as ${ }^{* *} \mathrm{p}<0.01$, was considered as significant. (B) Representative graph from the three independent experiments summarized in the bar diagram shown in Fig. 2A. All experiments were performed at least in triplicate. (C) Bar diagram summarizing the results of flow cytometric analysis of HEK293T cells stained with $0.5 \mu \mathrm{M}$ fluorescently labeled PDIA6. This interaction can be either reduced by addition of unlabeled KDEL peptide or unlabeled PDIA6. Fluorescently labeled IL-6 was used as a negative control, since HEK293T cells do not express IL-6R. P-values were calculated and are labeled regarding their significance with ${ }^{*} \mathrm{p}<0.05,{ }^{* *} \mathrm{p}<0.01$, ${ }^{* * *} \mathrm{p}<0.001$. (D) Representative graph of the experiment summarized in Fig. 2C.

might interact with endogenous PDIs or other interaction partners for which the cell surface presence is influenced by KDELR1. Immunoprecipitation and mass spectrometry might provide evidence supporting this suggestion, but because of the small quantity of interaction and the possibility of multiple interaction partners, this aspect was definitely beyond the scope of the work presented here.

The finding of endogenously expressed KDELR1 at the cell surface strengthens the notion that it is involved in the transport of ER-resident proteins. The effect of down regulated KDELR1 expression on the presence of three different PDIs, namely PDIA1 (PDI), PDIA3 (Erp57), and PDIA6 (Erp5), at the cell surface was tested. Wild-type cells and the two knockdown cell lines (clone 3 and clone 7 ) were analyzed by flow cytometry. For quantification, the mean fluorescence on wild-type cells was set to $100 \%$ cell surface interaction, and the mean fluorescence of the knock-down cell lines and negative control were normalized. Strikingly, both KDELR1 knock-down cell lines showed a reduced cell surface presence of all three endogenously expressed isomerases (Fig. 4F and 4G). As the expression of KDELR is only down regulated to $40 \%-60 \%$ in total, a reduction of the tested PDIs by $60-70 \%$ was considered to be efficient.

The transport of the KDELR1 and PDIs to the cell surface is dynamic

To gain first insights into the trafficking of endogenous KDELR1, cells were treated with various compounds that target either secretion or endocytosis. After 1.5 hours, the cells were harvested, and the cell surface presence of KDELR1 and of PDIA1, PDIA3, and PDIA6 was analyzed by flow cytometry. DMSO served as a control. The mean fluorescence intensity of the DMSO-treated samples was used for standardization and set to $100 \%$ of the cell surface presence in resting cells. Treatment of the cells with PMA, which has previously been shown to induce the secretion of PDIs into the extracellular space $[47,48]$, did not alter the cell surface presence of KDELR1 but decreased that of all three PDIs (Fig. 5A - 5E). Exemplary histograms of flow cytometric measurements are shown in Fig. 5A (for color-coding, see Fig. 5B). A summary of three independent experiments is presented in Fig. 5C (for significances, see Fig. 5D). A schematic drawing of the proposed secretion and endocytosis routes of PDIs and KDELR1 is given in Fig. 5E and 5F. 


\section{Cellular Physiology and Biochemistry

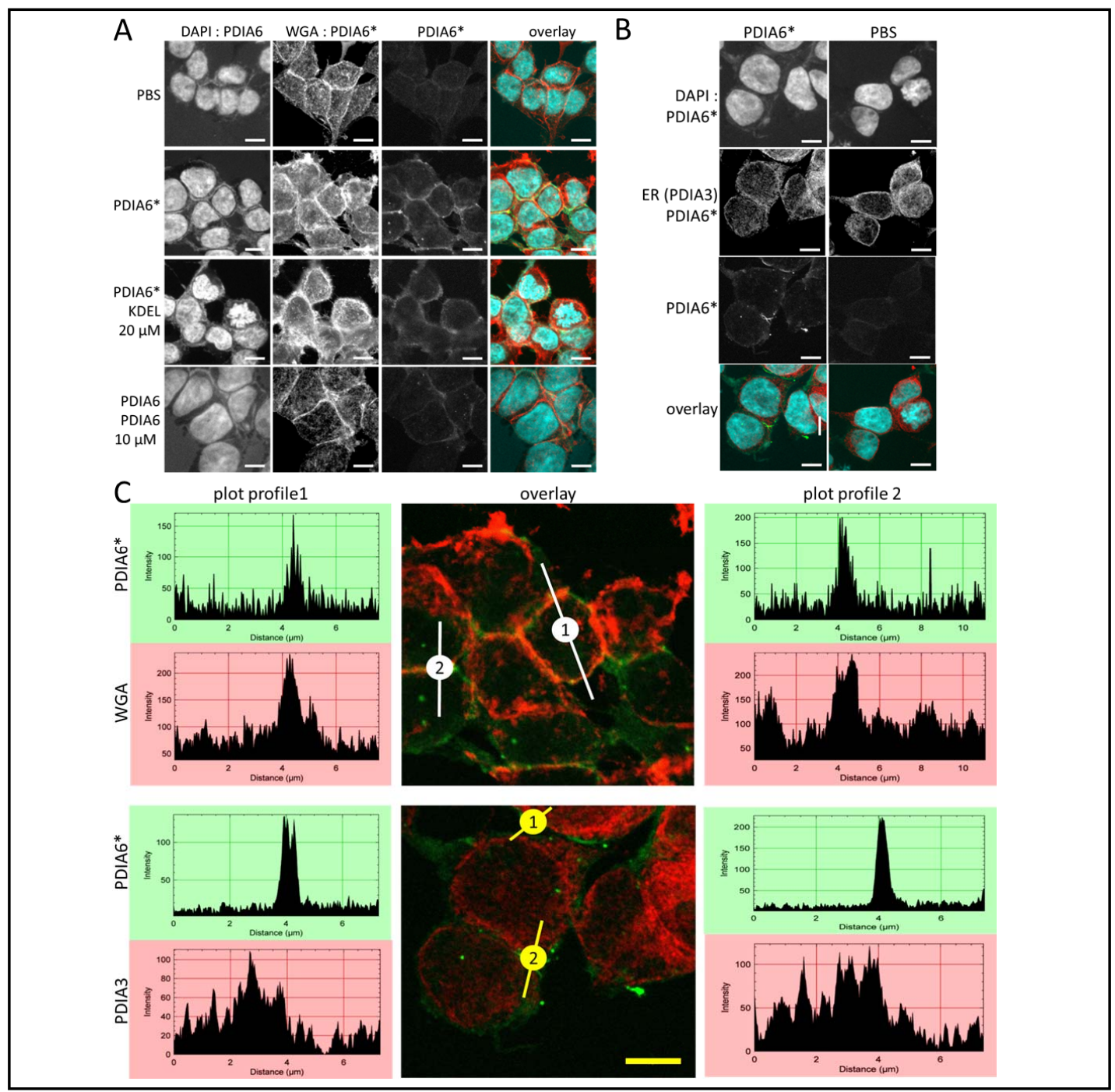

Fig. 3. (A) Fluorescently labeled PDIA6 (PDIA6*) associates with the cell surface of PDIA6. HEK293T cells were labeled for 3 hours with $3 \mu \mathrm{M}$ PDIA6* alone or in the presence of either $20 \mu \mathrm{M}$ KDEL peptide or $10 \mu \mathrm{M}$ unlabeled PDIA6. Afterwards, the cells were stained with DAPI and WGA, and images were taken. (B) Fluorescently labeled PDIA6 does not travel back into the ER. After incubation of HEK293T cells with fluorescently labeled PDIA6, cells were permeabilized and stained with DAPI and against PDIA3 as a marker of the ER. No colocalization could be detected. (C) Plot profile of co-staining with fluorescent labeled PDIA6* either with WGA (cell surface) or PDIA3 (ER). The plot profile shows the intensities of pixels along the indicated lines in the corresponding images. X-axis represents the horizontal distance through the selection and the $y$-axis the vertically averaged pixel intensity. Although values of pixel intensities differ for each dye, maximum intensities could be detected in green (PDIA6*) and red (WGA) in similar pattern but not in case of co-detection of green (PDIA6*) and red (PDIA3). (A-C) Scale bars indicate $5 \mu \mathrm{m}$.

Pitstop ${ }^{\circledR} 2$ and Genistein (GE) treatments were used to inhibit the clathrin-dependent endocytosis or the caveolin-dependent endocytosis, respectively. The amount of KDELR1 was enhanced in both treatments, suggesting internalization via clathrin- and caveolindependent endocytosis. Hence, the cell surface presence of KDELR1 was transient, and trafficking occurred even in unstimulated cells. In contrast, neither Pitstop® 2 nor GE altered PDIA1 at the cell surface in unstimulated cells. Thus, PDIA1 might not be significantly internalized, at least via these two pathways, in resting cells. PDIA3 and PDIA6 appeared to 


\section{Cellular Physiology Cell Physiol Biochem 2019;52:850-868

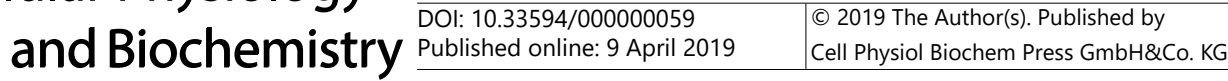 \\ Bartels et al.: Cell Surface Association of Protein Disulfide Isomerases}

be internalized constitutively via caveolin-dependent endocytosis, since treatment with GE increased their cell surface presence, whereas treatment with Pitstop $₫ 2$ did not.

The reductive effects of PMA on the cell surface presence of the PDIs were also visible in PMA co-treatments with GE or Pitstop ${ }^{\circledR}$ 2. Detailed examination revealed that PMA probably induced internalization via caveolin-dependent endocytosis. PDIA1 at the cell surface of the GE/PMA co-treated sample exhibited a significantly higher presence compared with that of the solely PMA-treated sample. PDIA6 showed the same tendency, but this was not significant. The amount of PDIA3 on the surface of the Pitstop® 2/ PMA co-treated sample was significantly reduced compared with solely PMA treated cells. Since caveolin-dependent endocytosis was not blocked, the reduction might be attributable to internalization via this pathway. Hence, the reduced amount of PDIA1 and PDIA3 at the surface of solely PMA-treated samples might be the result of enhanced internalization and secretion. Studies of the ratio of secretion and internalization and of the exact internalization pathway should be undertaken in the future, but the presented data clearly indicate that the cell surface presence of KDELR1 is dynamic. Furthermore, the fate and behavior of the cell surface PDIs are not completely uniform but appear to be unique for the single PDIs.

\section{Discussion}

ER-resident chaperons and isomerases have diverse functions at the cell surface. However, the way that these proteins, with a C-terminal KDEL sequence, escape the retrograde transport is still far from clear. One mechanism might be that these proteins escape the interaction with the KDELRs. Hence, they can travel along the classical secretory pathway to the cell surface. Their means of escape from the interaction with the KDELRs might differ. A second protein might be involved that masks the KDEL sequence, thereby preventing the interaction with the KDELRs and escorting the protein to the cell surface. Such a scenario has been described for the ER-resident chaperon GRP78, also known as BiP. Two proteins MTJ-1 [49] and Par-4 [50] have the capability to promote the transport of GRP78 to the cell surface. The lectin galectin-9 interacts with 0-glycosylated PDIA1 and supports its cell surface association. This interaction promotes typical functions of PDIs at the cell surface such as entry of the human deficiency virus into Th2 cells or migration via $\beta 3$ integrin [51, 52].

A second mechanism for overcoming the interaction with the KDELRs might be an overloading of the ER by proteins containing the KDEL sequence. This would lead to the saturation of the KDELRs, and some proteins, although carrying a KDEL sequence, would escape retrieval, pass the secretory pathway, and reach the plasma membrane. Such a scenario would be conceivable in the case of ER stress, where the expression of ER-resident chaperons and isomerases are upregulated [53-55] and transported to the cell surface and/ or secreted into the extracellular space $[18,56]$. The transport and cell surface association of overexpressed PDIA6 variants are probably not attributable to the saturation of the KDELRs, since strong overexpression results in no detectable secretion, even by immunoprecipitation (Fig. 1C and 1D). Furthermore, the overexpression of PDIA6wo variants leads to secretion but does not favor cell surface association. Hence, a saturation of the KDELRs seems difficult to achieve, and the possibility of escape remains to be established, although the capacity of KDELRs might be variable in different cell types.

An increase in the secretion of ER-resident proteins lacking their C-terminal KDEL sequence has been previously observed [57-60]. The reduced cell surface association is in contrast to the results of the overexpressed GRP78 without its KDEL sequence (GRP78wo) whose cell surface association is not significantly diminished by the lack of the KDEL sequence [60]. These differences might be attributable to differences in transport. Whereas the transport of PDIA6 depends on its KDEL sequence, GRP78 is transported in a complex with proteins that are thought to mask the KDEL sequence. These interactions of GRP78 might be still possible in the case of a lack of the KDEL sequence. Although some of the 


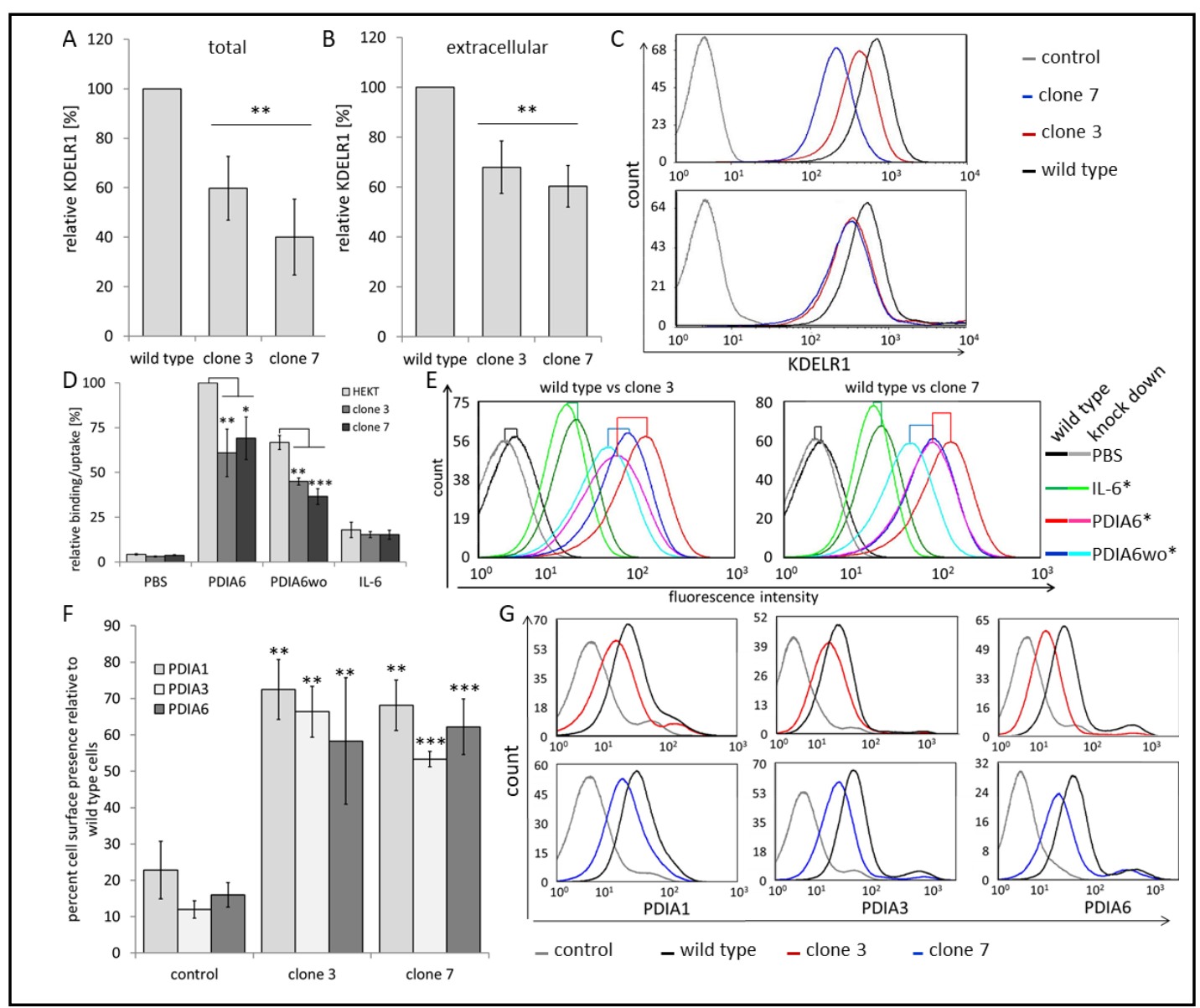

Fig. 4. The transport of cell surface localized PDIs is influenced by KDELR1. (A) The reduced expression of the KDELR1 in two HEK293T cell lines, created by shRNA, was analyzed by flow cytometry with permeabilized cells. The bar diagram shows average mean values and standard deviations of at least three independent experiments. Following Student's test, the calculated $p$ values were ${ }^{* *} \mathrm{p}<0.01$ and therefore considered as significant. (B) KDELR1 can be detected on the cell surface of non permeabilized HEK293T cells. The cell surface association of KDELR1 was comparably reduced at the cell surface of the KDELR1 knock-down cell lines. Following Student's test, the calculated ${ }^{* *} \mathrm{p}<0.01$ was considered as significant. (C) Typical graphs of the flow cytometric analysis summarized in Fig. 4A (upper panel) and 4B (lower panel. (D) Down regulation of KDELR1 expression reduces cell association of PDIA6 and PDIA6wo. Wild-type and KDELR1 knock-down clone 3 and clone 7 cell lines were either incubated with PBS or with fluorescently labeled proteins: PDIA6, PDIA6wo, or IL-6. After 30 minutes, cells where washed and analyzed by flow cytometry. Binding of PDIA6 was significantly reduced in the knock-down cell line as indicated by the asterisks. ${ }^{*} \mathrm{p}<0.05,{ }^{* *} \mathrm{p}<0.01$, and ${ }^{* * *} \mathrm{p}<0.001$ were considered as significant. Additionally, the interaction of PDIA6wo was reduced in KDELR1 knock-down cell lines. (E) Representative graphs of the flow cytometric analysis shown in Fig. 4D. (F) Bar diagram summarizing the flow cytometric analysis of the cell surface expression of three different PDIs (PDIA1, PDIA3, and PDIA6) well known as being located at the cell surface. The analysis was performed at least three times independently, with wild-type HEK293T cells and with two KDELR knock-down cell lines. Significance is indicated by ${ }^{* *} \mathrm{p}<0.01$ and ${ }^{* * *} \mathrm{p}<0.001$. The control samples were only treated with secondary antibody and not primary antibodies. (G) Examples of flow cytometric analysis summarized in Fig. 4F. 


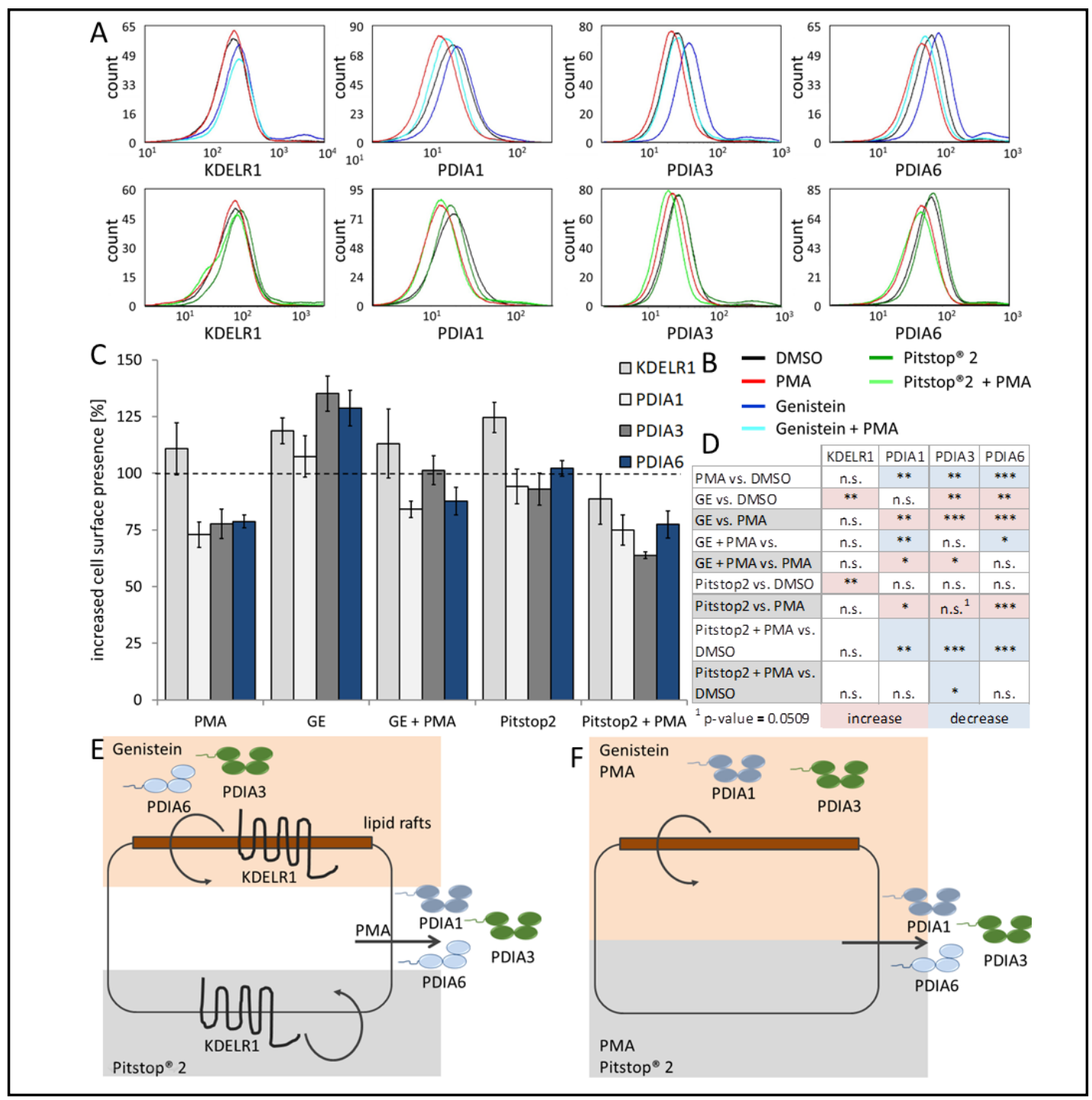

Fig. 5. The transport of the KDELR1 and PDIs to the plasma membrane is dynamic. (A) Representative graphs of the flow cytometric analysis of the cell surface expression of KDELR1, PDIA1, PDIA3, and PDIA6 after treatment as indicated in Fig. 5B. (B) Before staining, cells were treated with DMSO, Pitstop® 2 (inhibitor of clathrin-dependent endocytosis), Genistein (GE, inhibitor of caveolin-dependent endocytosis), PMA (activator of protein kinase C), PMA with GE, or PMA with Pitstop® 2 for 1.5 hours. (C) A bar diagram summarizing the results of three independent flow cytometric analyses presented in Fig. 5A. (D) Overview of the up (red) and down (blue) regulated cell surface presence of the indicated proteins following the various treatments, with indicated significances with respect to either DMSO- or PMA-treated samples. (E) Schematic drawing of the secretion of PDIs upon PMA treatment and increased cell surface presence attributable to the blockade of the caveolin-dependent pathway (GE) or clathrin-dependent pathway (Pitstop® 2). KDELR1 is endocytosed via both pathways. In resting cells, PDIA3 and PDIA6 are endocytosed via the caveolin-dependent route. (F) Co-treatment of HEK293T cells with PMA and GE or Pitstop® 2 results in decreased cell surface presence compared with corresponding samples without PMA, probably because of the secretion of PDIs. Comparison of solely PMA-treated and the GE/ PMA co-treated samples showing a significant increase in the cell surface presence of PDIA1 in the GE-treated sample because of decreased endocytosis via the caveolin-dependent pathway. The Pitstop ${ }^{\circledR}$ 2/ PMA co-treated samples exhibit a significant decrease in the cell surface presence of PDIA3 in the case of the PMA only treatment. This might also be the result of to a reduction of PDIA3 at the cell surface caused by an increase in caveolin-dependent endocytosis attributable to PMA stimulation. 
GRP78wo might be secreted, some might still be transported in protein complexes. Another reason for the higher cell surface association of GRP78wo might be that it exhibits more interaction partners and/or binds interaction partners with a higher affinity compared with PDIA6wo.

Although the overexpression of PDIA6wo resulted in a diminished cell surface association, exogenously added recombinant PDIA6wo was detected at HEK293T cells by flow cytometry (Fig. 2A and 2B). At first glance, this result seems surprisingly, but it is most likely caused by the high concentration of proteins during incubation $(0.5 \mu \mathrm{M}$ corresponding to $24.2 \mathrm{mg} / \mathrm{l}$ PDIA6). Such concentrations are unlikely to be achieved by non-optimized overexpression $[61,62]$. The fluorescently labeled PDIA6wo binds with 30\% lower efficiency than PDIA6 but clearly more strongly than the negative control IL-6. The notable interaction of PDIA6wo indicates additional binding sites in PDIA6, different from the KDEL sequence. Additional binding sites, in addition to the KDEL sequence, have been demonstrated for calreticulin. Here, they retain the chaperon in the secretory pathway. Hence, calreticulin without its KDEL sequence is secreted with a lower efficiency than a classical secreted protein [59]. The cell surface interaction of PDIA6 can be reasonably suggested to depend not only on its KDEL sequence, since extracellular substrates of PDIA6, such as the MICA [16] and ADAM17 [28, 29], are expressed in HEK293 cells [63]. The latter interacts with PDIA1, PDIA3, and PDIA6 in a high nanomolar range [43]. An increase in cell surface association by lectins, as established for PDIA1 might be, at least for galectin 9, questionable, since HEK293 cells express the lectin only to minor extend [63].

The association of PDIA6 with the cells was competed by the KDEL peptide, indicating that KDELRs are involved in this process (Fig. 3A), opening a further pathway to the cell surface via the KDELRs. KDELR1 is involved in the increase in cell surface PDIA1 triggered by Dengue virus infection [64]. The knock-down of KDELR1 strongly indicates that the cell surface trafficking of PDIs also depends on KDELR1 in resting cells (Fig. 4F and 4G). Our fluorescence images show that exogenously added PDIA6 associates with the cell surface and is internalized (Fig. 3A). Since endogenous expressed KDELR1 is detectable at the cell surface (Fig. 4A-4C), one can exclude that the cell surface presence of overexpressed KDELR1 shown in previous reports is an artefact of overexpression $[65,66]$. Hence, KDELR1 can transport the cargo to the cell surface but, because of the increase in $\mathrm{pH}$, it is likely to be released. This release probably occurs in specifically targeted micro-domains of the membrane and in its close proximity. Both can support the interaction of PDIA6 with various partners at the cell surface, and this would explain the robust reduction in the cell association of PDIA6wo overexpression.

Exogenously added PDIA6 does not co-localize with the ER upon internalization (Fig. $3 \mathrm{~A}$ ). This might be attributable to the circumstance that the KDELRs bind their cargos only with low affinity at the cell surface because of the neutral $\mathrm{pH}$. The resulting low affinity binding can allow short-time interactions, but not internalization and retrograde transport to the Golgi apparatus and ER. Alternatively, the KDELRs with their cargo are internalized and transported into compartments different from the ER. We cannot exclude that the KDEL sequence binds to other targets on the cell surface, in addition to the KDELRs. Hence, many more questions remain about the trafficking route of the KDELRs and its cargo and will be an interesting task to solve in future research. This includes the questions regarding the way that the cargos are released at the surface and the kinetics of trafficking.

The cell surface presence of PDIA1, PDIA3, and PDIA6 depends on KDELR1 (Fig. 4F and 4G), although first insights into their trafficking have shown different actions (Fig. 5). PMA has previously been reported to increase the secretion of isomerases [47, 48], and as a consequence, the cell surface presence of all three isomerases decreases following PMA treatment. In contrast, the amount of KDELR1 is unaffected. KDELR1 seems to be internalized via clathrin- or caveolin-dependent endocytosis, since treatment with respective inhibitors increases its cell surface presence. In contrast, PDIA3 and PDIA6 are solely internalized out of lipid rafts regions in cells that are not stimulated with PMA. In the case of PDIA1 and PDIA3, PMA appears to increase caveolin-dependent endocytosis via lipid raft regions. None 


\section{Cellular Physiology Cell Physiol Biochem 2019;52:850-868 \\ \begin{tabular}{ll|l} 
DOl: 10.33594/000000059 & $\begin{array}{l}\text { O } 2019 \text { The Author(s). Published by } \\
\text { Cell Physiol Biochem Press GmbH\&Co. KG }\end{array}$ \\
\cline { 2 - 3 }
\end{tabular} \\ Bartels et al.: Cell Surface Association of Protein Disulfide Isomerases}

of the analyzed PDIs seems to be endocytosed via clathrin-dependent endocytosis. This first insight into trafficking is only minor and requires further investigations, but it suggests differences in the trafficking of KDELR1 and its cargo supporting the hypothesis that KDELR1 releases its cargo at the cell surface. Differences in trafficking have to be further questioned and might vary under different stimuli and cell types. At least two different pathways for PDIs towards the plasma membrane exist [48, 67], probably depending on whether the PDIs are to be secreted or associated with the cell surface. Whereas cell surface association is locally restricted at the cell, e.g., by the inactivation of ADAM17 [28, 29], the activation of integrins [20-25] or the sensitizing of MICA and MICB for shedding and release from the cell surface, to protect cells from cell death mediated by natural killer cells [16]. Secretion might be a further step for promoting a more global answer, as in coagulation in which PDIs are secreted from various cell types, such as platelets and endothelial cells, to promote a strong and fast response [23-25, $47,68,69]$. PDIs are stored in granules for fast release $[21,47,70,71]$. Such secretion is probably inducible by PMA and bypasses the classic route via the Golgi apparatus as described for TNF $\alpha$ [48]. This independency fits with the PMAinduced reduced cell surface association of the analyzed PDIs and the unaffected cell surface presence of KDELR1. In contrast, the cell surface association might depend on KDELR1, which is most likely a Golgi-dependent transport, since Dengue-virus-induced transport is sensitive to Brefeldin A treatment. In agreement, not only overexpressed KDELRs, but also various chaperons show increased cell surface association during ER stress $[18,60,65,66$, 72].

The use and impact of the different routes, the transport to the cell surface via the Golgi apparatus or secretion by vesicles, as well as the transport mechanism through the Golgi apparatus might be different in distinct cell types and environmental conditions. Shedding light on the detailed scenarios will be a challenge. Regarding the transport of the ER resident proteins to the cell surface via the Golgi apparatus at least two ways exist. In one the KDEL sequence is needed for the transport by the KDELR1 and in the second the KDEL sequence is hidden by complex formation. To clarify whether one protein uses always the same mechanism will be an interesting task.

In the case of the KDELR1 in HEK293T cells, simple overexpression was sufficient for its detection at the cell surface $[65,66]$. The other three KDELRs, which prefer the HDEL sequence, required ER stress to be detectable at the cell surface [65]. This might be attributable to selectivity. KDELR1 might be mainly involved in the constitutive and probably inducible transport of proteins that contain a KDEL sequence rather than an HDEL sequence. Hence, KDEL-containing proteins are favored for cell surface association rather than proteins carrying an HDEL sequence. Multiple means might exist for transporting isomerases and chaperons to the cell surface. One of these might be KDELR1-dependent, although complex formation seems also to be prevalently used.

\section{Conclusion}

PDIs have various functions at the cell surface and travel via diverse pathways. Cell surface associated PDIs act locally on individual cells and probably depend on a Golgidependent pathway coupled to KDELR1. The increase in $\mathrm{pH}$ at the cell surface seems to favor their release in close proximity to their special targets. Secretion and a global action might thus be prevented. In contrast, for global actions, such as coagulation, PDIs might be secreted in preformed vesicles in a Golgi-independent way in order to target multiple cells and cell types. 


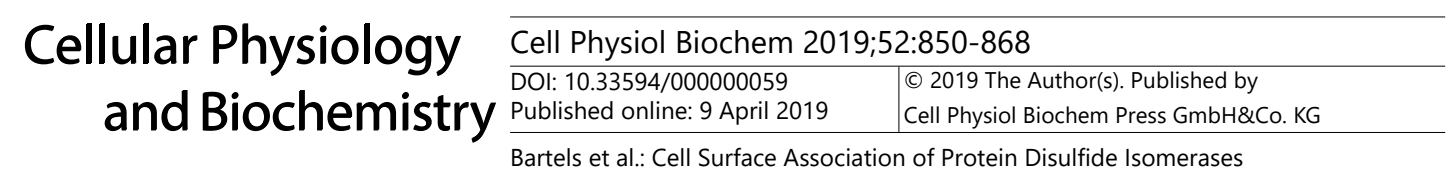

\section{Abbreviations}

ADAM (A Disintegrin and Metalloprotease); clMPD (closed MPD); CANDIS (Conserved ADAM seventeeN Interaction Sequence); DMEM (Dulbecco Modified Eagle Medium); DMSO (dimethyl sulfoxide); ER (endoplasmic reticulum); FCS (fetal calf serum); GE (Genistein); GRP78wo (GRP78 without its KDEL sequence); IL (interleukin); KDELR (KDEL receptor); MIC (Major Histocompatibility Complex class I chain-related molecule A); MPD (membraneproximal domain); opMPD (open MPD); PBS (phosphate-buffered saline); PDI (protein disulfide isomerase); PDIA6wo (PDIA6 without KDEL sequence); PMA (phorbol-12myristate-13-acetate); PC (Protein C); PS (phosphatidylserine); TNF (Tumor Necrosis Factor); Wo (without).

\section{Acknowledgements}

The authors thank Brigitte Bittner for her excellent technical assistance, Christoph Plieth for critical reading of this manuscript and Björn Rabe for support in the knockdown of KDELR1 in HEK293T cell lines and gratefully acknowledge access to the core facilities of the BiMo/LMB of the Kiel University. This study was supported by the Deutsche Forschungsgemeinschaft (SFB 877 (A6) and SPP1710, LO 1722/1-2).

\section{Disclosure Statement}

The authors have no conflicts of interest.

\section{References}

1 Wilson DW, Lewis MJ, Pelham HR: pH-dependent binding of KDEL to its receptor in vitro. J Biol Chem 1993;268:7465-7468.

2 Lewis MJ, Pelham HR: Ligand-induced redistribution of a human KDEL receptor from the Golgi complex to the endoplasmic reticulum. Cell 1992;68:353-364.

3 Townsley FM, Wilson DW, Pelham HR: Mutational analysis of the human KDEL receptor: distinct structural requirements for Golgi retention, ligand binding and retrograde transport. EMBO J 1993;12:2821-2829.

4 Aoe T, Cukierman E, Lee A, Cassel D, Peters PJ, Hsu VW: The KDEL receptor, ERD2, regulates intracellular traffic by recruiting a GTPase-activating protein for ARF1. EMBO J 1997;16:7305-7316.

5 Cabrera M, Muniz M, Hidalgo J, Vega L, Martin ME, Velasco A: The retrieval function of the KDEL receptor requires PKA phosphorylation of its C-terminus. Mol Biol Cell 2003;14:4114-4125.

6 Martin ME, Hidalgo J, Rosa JL, Crottet P, Velasco A: Effect of protein kinase A activity on the association of ADP-ribosylation factor 1 to golgi membranes. J Biol Chem 2000;275:19050-19059.

7 Lewis MJ, Pelham HR: A human homologue of the yeast HDEL receptor. Nature 1990;348:162-163.

- 8 Lewis MJ, Pelham HR: Sequence of a second human KDEL receptor. J Mol Biol 1992;226:913-916.

- 9 Raykhel I, Alanen H, Salo K, Jurvansuu J, Nguyen VD, Latva-Ranta M, Ruddock L: A molecular specificity code for the three mammalian KDEL receptors. J Cell Biol 2007;179:1193-1204.

10 Graul RC, Sadee W: Evolutionary relationships among G protein-coupled receptors using a clustered database approach. AAPS PharmSci 2001;3:E12.

11 Giannotta M, Ruggiero C, Grossi M, Cancino J, Capitani M, Pulvirenti T, Consoli GM, Geraci C, Fanelli F, Luini A, Sallese M: The KDEL receptor couples to Galphaq/11 to activate Src kinases and regulate transport through the Golgi. EMBO J 2012;31:2869-2881.

12 Cancino J, Capalbo A, Di Campli A, Giannotta M, Rizzo R, Jung JE, Di Martino R, Persico M, Heinklein P, Sallese M, Luini A: Control systems of membrane transport at the interface between the endoplasmic reticulum and the Golgi. Dev Cell 2014;30:280-294. 


\section{Cellular Physiology Cell Physiol Biochem 2019;52:850-868 \begin{tabular}{ll|l}
\hline DOI: 10.33594/000000059 & ( 2019 The Author(s). Published by \\
\hline and Biochemistry
\end{tabular} and Biochemistry Published online: 9 April 2019 Cell Physiol Biochem Press GmbH\&Co. KG \\ Bartels et al.: Cell Surface Association of Protein Disulfide Isomerases}

- 13 Pulvirenti T, Giannotta M, Capestrano M, Capitani M, Pisanu A, Polishchuk RS, San Pietro E, Beznoussenko GV, Mironov AA, Turacchio G, Hsu VW, Sallese M, Luini A: A traffic-activated Golgi-based signalling circuit coordinates the secretory pathway. Nat Cell Biol 2008;10:912-922.

- 14 Yoshimori T, Semba T, Takemoto H, Akagi S, Yamamoto A, Tashiro Y: Protein disulfide-isomerase in rat exocrine pancreatic cells is exported from the endoplasmic reticulum despite possessing the retention signal. J Biol Chem 1990;265:15984-15990.

- 15 Xiao G, Chung TF, Pyun HY, Fine RE, Johnson RJ: KDEL proteins are found on the surface of NG108-15 cells. Brain Res Mol Brain Res 1999;72:121-128.

16 Kaiser BK, Yim D, Chow IT, Gonzalez S, Dai Z, Mann HH, Strong RK, Groh V, Spies T: Disulphide-isomeraseenabled shedding of tumour-associated NKG2D ligands. Nature 2007;447:482-486.

17 Swiatkowska M, Szymanski J, Padula G, Cierniewski CS: Interaction and functional association of protein disulfide isomerase with alphaVbeta3 integrin on endothelial cells. FEBS J 2008;275:1813-1823.

18 Peters LR, Raghavan M: Endoplasmic reticulum calcium depletion impacts chaperone secretion, innate immunity, and phagocytic uptake of cells. J Immunol 2011;187:919-931.

19 Huergo-Zapico L, Gonzalez-Rodriguez AP, Contesti J, Gonzalez E, Lopez-Soto A, Fernandez-Guizan A, Acebes-Huerta A, de Los Toyos JR, Lopez-Larrea C, Groh V, Spies T, Gonzalez S: Expression of ERp5 and GRP78 on the membrane of chronic lymphocytic leukemia cells: association with soluble MICA shedding. Cancer Immunol Immunother 2012;61:1201-1210.

20 Lahav J, Gofer-Dadosh N, Luboshitz J, Hess O, Shaklai M: Protein disulfide isomerase mediates integrindependent adhesion. FEBS Lett 2000;475:89-92.

- 21 Jordan PA, Stevens JM, Hubbard GP, Barrett NE, Sage T, Authi KS, Gibbins JM: A role for the thiol isomerase protein ERP5 in platelet function. Blood 2005;105:1500-1507.

22 Cho J, Furie BC, Coughlin SR, Furie B: A critical role for extracellular protein disulfide isomerase during thrombus formation in mice. J Clin Invest 2008;118:1123-1131.

23 Kim K, Hahm E, Li J, Holbrook LM, Sasikumar P, Stanley RG, Ushio-Fukai M, Gibbins JM, Cho J: Platelet protein disulfide isomerase is required for thrombus formation but not for hemostasis in mice. Blood 2013;122:1052-1061.

24 Holbrook LM, Sasikumar P, Stanley RG, Simmonds AD, Bicknell AB, Gibbins JM: The platelet-surface thiol isomerase enzyme ERp57 modulates platelet function. J Thromb Haemost 2012;10:278-288.

25 Passam FH, Lin L, Gopal S, Stopa JD, Bellido-Martin L, Huang M, Furie BC, Furie B: Both platelet- and endothelial cell-derived ERp5 support thrombus formation in a laser-induced mouse model of thrombosis. Blood 2015;125:2276-2285.

26 Gallina A, Hanley TM, Mandel R, Trahey M, Broder CC, Viglianti GA, Ryser HJ: Inhibitors of protein-disulfide isomerase prevent cleavage of disulfide bonds in receptor-bound glycoprotein 120 and prevent HIV-1 entry. J Biol Chem 2002;277:50579-50588.

- 27 Markovic I, Stantchev TS, Fields KH, Tiffany LJ, Tomic M, Weiss CD, Broder CC, Strebel K, Clouse KA: Thiol/ disulfide exchange is a prerequisite for CXCR4-tropic HIV-1 envelope-mediated T-cell fusion during viral entry. Blood 2004;103:1586-1594.

28 Düsterhöft S, Jung S, Hung CW, Tholey A, Sönnichsen FD, Grötzinger J, Lorenzen I: Membrane-proximal domain of a disintegrin and metalloprotease-17 represents the putative molecular switch of its shedding activity operated by protein-disulfide isomerase. J Am Chem Soc 2013;135:5776-5781.

29 Willems SH, Tape CJ, Stanley PL, Taylor NA, Mills IG, Neal DE, McCafferty J, Murphy G: Thiol isomerases negatively regulate the cellular shedding activity of ADAM17. Biochem J 2010;428:439-450.

30 Reddy P, Slack JL, Davis R, Cerretti DP, Kozlosky CJ, Blanton RA, Shows D, Peschon JJ, Black RA: Functional analysis of the domain structure of tumor necrosis factor-alpha converting enzyme. J Biol Chem 2000;275:14608-14614.

31 Lorenzen I, Trad A, Grötzinger J: Multimerisation of A disintegrin and metalloprotease protein-17 (ADAM17) is mediated by its EGF-like domain. Biochem Biophys Res Commun 2011;415:330-336.

- 32 Lorenzen I, Lokau J, Düsterhoft S, Trad A, Garbers C, Scheller J, Rose-John S, Grötzinger J: The membraneproximal domain of A Disintegrin and Metalloprotease 17 (ADAM17) is responsible for recognition of the interleukin-6 receptor and interleukin-1 receptor II. FEBS Lett 2012;586:1093-1100. 


\section{Cellular Physiology Cell Physiol Biochem 2019;52:850-868

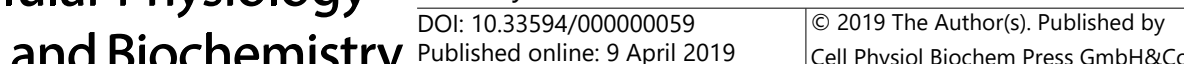 and Biochemistry Published online: 9 April 2019 Cell Physiol Biochem Press GmbH\&Co. KG \\ Bartels et al.: Cell Surface Association of Protein Disulfide Isomerases}

33 Sommer A, Kordowski F, Buch J, Maretzky T, Evers A, Andra J, Düsterhöft S, Michalek M, Lorenzen I, Somasundaram P, Tholey A, Sönnichsen FD, Kunzelmann K, Heinbockel L, Nehls C, Gutsmann T, Grötzinger J, Bhakdi S, Reiss K: Phosphatidylserine exposure is required for ADAM17 sheddase function. Nat Commun 2016;7:11523.

- 34 Düsterhöft S, Höbel K, Oldefest M, Lokau J, Waetzig GH, Chalaris A, Garbers C, Scheller J, Rose-John S, Lorenzen I, Grötzinger J: A Disintegrin and Metalloprotease 17 Dynamic Interaction Sequence, the Sweet Tooth for the Human Interleukin 6 Receptor. J Biol Chem 2014;289:16336-16348.

- 35 Düsterhöft S, Michalek M, Kordowski F, Oldefest M, Sommer A, Roseler J, Reiss K, Grötzinger J, Lorenzen I: Extracellular Juxtamembrane Segment of ADAM17 Interacts with Membranes and Is Essential for Its Shedding Activity. Biochemistry 2015;54:5791-5801.

- 36 Göoz M: ADAM-17: the enzyme that does it all. Crit Rev Biochem Mol Biol 2010;45:146-169.

- 37 Le Gall SM, Maretzky T, Issuree PD, Niu XD, Reiss K, Saftig P, Khokha R, Lundell D, Blobel CP: ADAM17 is regulated by a rapid and reversible mechanism that controls access to its catalytic site. J Cell Sci 2010;123:3913-3922.

38 Peschon JJ, Slack JL, Reddy P, Stocking KL, Sunnarborg SW, Lee DC, Russell WE, Castner BJ, Johnson RS, Fitzner JN, Boyce RW, Nelson N, Kozlosky CJ, Wolfson MF, Rauch CT, Cerretti DP, Paxton RJ, March CJ, Black RA: An essential role for ectodomain shedding in mammalian development. Science 1998;282:1281-1284.

- 39 Black RA, Rauch CT, Kozlosky CJ, Peschon JJ, Slack JL, Wolfson MF, Castner BJ, Stocking KL, Reddy P, Srinivasan S, Nelson N, Boiani N, Schooley KA, Gerhart M, Davis R, Fitzner JN, Johnson RS, Paxton RJ, March CJ, Cerretti DP: A metalloproteinase disintegrin that releases tumour-necrosis factor-alpha from cells. Nature 1997;385:729-733.

- 40 Moss ML, Jin SL, Milla ME, Bickett DM, Burkhart W, Carter HL, Chen WJ, Clay WC, Didsbury JR, Hassler D, Hoffman CR, Kost TA, Lambert MH, Leesnitzer MA, McCauley P, McGeehan G, Mitchell J, Moyer M, Pahel $\mathrm{G}$, Rocque W, et al.: Cloning of a disintegrin metalloproteinase that processes precursor tumour-necrosis factor-alpha. Nature 1997;385:733-736.

41 Riethmueller S, Ehlers JC, Lokau J, Düsterhoft S, Knittler K, Dombrowsky G, Grötzinger J, Rabe B, RoseJohn S, Garbers C: Cleavage Site Localization Differentially Controls Interleukin-6 Receptor Proteolysis by ADAM10 and ADAM17. Sci Rep 2016;6:25550.

42 Müllberg J, Oberthur W, Lottspeich F, Mehl E, Dittrich E, Graeve L, Heinrich PC, Rose-John S: The soluble human IL-6 receptor. Mutational characterization of the proteolytic cleavage site. J Immunol 1994;152:4958-4968.

- 43 Krossa S, Scheidig AJ, Grötzinger J, Lorenzen I: Redundancy of protein disulfide isomerases in the catalysis of the inactivating disulfide switch in A Disintegrin and Metalloprotease 17. Sci Rep 2018;8:1103.

- 44 Schäfer M, Granato DC, Krossa S, Bartels AK, Yokoo S, Düsterhöft S, Koudelka T, Scheidig AJ, Tholey A, Paes Leme AF, Grötzinger J, Lorenzen I: GRP78 protects a disintegrin and metalloprotease 17 against proteindisulfide isomerase A6 catalyzed inactivation. FEBS Lett 2017;591:3567-3587.

- 45 Ran FA, Hsu PD, Wright J, Agarwala V, Scott DA, Zhang F: Genome engineering using the CRISPR-Cas9 system. Nat Protoc 2013;8:2281-2308.

- 46 Hamada H, Suzuki M, Yuasa S, Mimura N, Shinozuka N, Takada Y, Suzuki M, Nishino T, Nakaya H, Koseki H, Aoe T: Dilated cardiomyopathy caused by aberrant endoplasmic reticulum quality control in mutant KDEL receptor transgenic mice. Mol Cell Biol 2004;24:8007-8017.

47 Jasuja R, Furie B, Furie BC: Endothelium-derived but not platelet-derived protein disulfide isomerase is required for thrombus formation in vivo. Blood 2010;116:4665-4674.

48 Araujo TLS, Zeidler JD, Oliveira PVS, Dias MH, Armelin HA, Laurindo FRM: Protein disulfide isomerase externalization in endothelial cells follows classical and unconventional routes. Free Radic Biol Med 2017;103:199-208.

- 49 Misra UK, Gonzalez-Gronow M, Gawdi G, Pizzo SV: The role of MTJ-1 in cell surface translocation of GRP78, a receptor for alpha 2-macroglobulin-dependent signaling. J Immunol 2005;174:2092-2097.

- 50 Burikhanov R, Zhao Y, Goswami A, Qiu S, Schwarze SR, Rangnekar VM: The tumor suppressor Par-4 activates an extrinsic pathway for apoptosis. Cell 2009;138:377-388. 


\section{Cellular Physiology Cell Physiol Biochem 2019;52:850-868

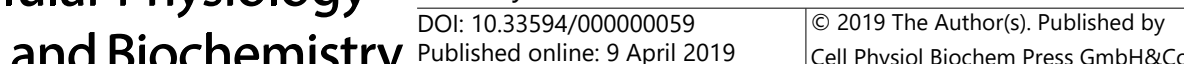 and Biochemistry Published online: 9 April 2019 Cell Physiol Biochem Press GmbH\&Co. KG \\ Bartels et al.: Cell Surface Association of Protein Disulfide Isomerases}

- 51 Bi S, Hong PW, Lee B, Baum LG: Galectin-9 binding to cell surface protein disulfide isomerase regulates the redox environment to enhance T-cell migration and HIV entry. Proc Natl Acad Sci U S A 2011;108:1065010655.

- 52 Schaefer K, Webb NE, Pang M, Hernandez-Davies JE, Lee KP, Gonzalez P, Douglass MV, Lee B, Baum LG: Galectin-9 binds to O-glycans on protein disulfide isomerase. Glycobiology 2017;27:878-887.

- 53 Okada K, Chen WT, Iwasa S, Jin X, Yamane T, Ooi A, Mitsumata M: Seprase, a membrane-type serine protease, has different expression patterns in intestinal- and diffuse-type gastric cancer. Oncology 2003;65:363-370.

- 54 Lee AH, Iwakoshi NN, Glimcher LH: XBP-1 regulates a subset of endoplasmic reticulum resident chaperone genes in the unfolded protein response. Mol Cell Biol 2003;23:7448-7459.

55 Li S, Zhao F, Cheng S, Wang X, Hao Y: Uric acid-induced endoplasmic reticulum stress triggers phenotypic change in rat glomerular mesangial cells. Nephrology (Carlton) 2013;18:682-689.

56 Delpino A, Castelli M: The $78 \mathrm{kDa}$ glucose-regulated protein (GRP78/BIP) is expressed on the cell membrane, is released into cell culture medium and is also present in human peripheral circulation. Biosci Rep 2002;22:407-420.

57 Vuori K, Pihlajaniemi T, Myllyla R, Kivirikko KI: Site-directed mutagenesis of human protein disulphide isomerase: effect on the assembly, activity and endoplasmic reticulum retention of human prolyl 4-hydroxylase in Spodoptera frugiperda insect cells. EMBO J1992;11:4213-4217.

- 58 Ko MK, Kay EP: PDI-mediated ER retention and proteasomal degradation of procollagen I in corneal endothelial cells. Exp Cell Res 2004;295:25-35.

- 59 Sönnichsen B, Fullekrug J, Nguyen Van P, Diekmann W, Robinson DG, Mieskes G: Retention and retrieval: both mechanisms cooperate to maintain calreticulin in the endoplasmic reticulum. J Cell Sci 1994;107:2705-2717.

- 60 Zhang Y, Liu R, Ni M, Gill P, Lee AS: Cell surface relocalization of the endoplasmic reticulum chaperone and unfolded protein response regulator GRP78/BiP. J Biol Chem 2010;285:15065-15075.

61 Subedi GP, Johnson RW, Moniz HA, Moremen KW, Barb A: High Yield Expression of Recombinant Human Proteins with the Transient Transfection of HEK293 Cells in Suspension. J Vis Exp 2015:e53568.

62 Jäger V, Büssow K, Wagner A, Weber S, Hust M, Frenzel A, Schirrmann T: High level transient production of recombinant antibodies and antibody fusion proteins in HEK293 cells. BMC Biotechnol 2013;13:52.

63 Thul PJ, Akesson L, Wiking M, Mahdessian D, Geladaki A, Blal HA, Alm T, Asplund A, Bjork L, Breckels LM, Backstrom A, Danielsson F, Fagerberg L, Fall J, Gatto L, Gnann C, Hober S, Hjelmare M, Johansson F, Lee S, et al.: A subcellular map of the human proteome. Science 2017;356:pii:eaal3321.

64 Wan SW, Lin CF, Lu YT, Lei HY, Anderson R, Lin YS: Endothelial cell surface expression of protein disulfide isomerase activates beta1 and beta3 integrins and facilitates dengue virus infection. J Cell Biochem 2012;113:1681-1691.

65 Henderson MJ, Richie CT, Airavaara M, Wang Y, Harvey BK: Mesencephalic astrocyte-derived neurotrophic factor (MANF) secretion and cell surface binding are modulated by KDEL receptors. J Biol Chem 2013;288:4209-4225.

66 Becker B, Shaebani MR, Rammo D, Bubel T, Santen L, Schmitt MJ: Cargo binding promotes KDEL receptor clustering at the mammalian cell surface. Sci Rep 2016;6:28940.

67 Araujo TLS, Fernandes CG, Laurindo FRM: Golgi-independent routes support protein disulfide isomerase externalization in vascular smooth muscle cells. Redox Biol 2017;12:1004-1010.

68 Wang L, Wu Y, Zhou J, Ahmad SS, Mutus B, Garbi N, Hammerling G, Liu J, Essex DW: Platelet-derived ERp57 mediates platelet incorporation into a growing thrombus by regulation of the alphallbbeta3 integrin. Blood 2013;122:3642-3650.

69 Holbrook LM, Watkins NA, Simmonds AD, Jones CI, Ouwehand WH, Gibbins JM: Platelets release novel thiol isomerase enzymes which are recruited to the cell surface following activation. Br J Haematol 2010;148:627-637.

70 Thon JN, Peters CG, Machlus KR, Aslam R, Rowley J, Macleod H, Devine MT, Fuchs TA, Weyrich AS, Semple JW, Flaumenhaft R, Italiano JE, Jr: T granules in human platelets function in TLR9 organization and signaling. J Cell Biol 2012;198:561-574. 


\section{Cellular Physiology Cell Physiol Biochem 2019;52:850-868}

\begin{tabular}{ll|l} 
and Bol: $10.33594 / 000000059$ & O 2019 The Author(s). Published by \\
Cell Physiol Biochem Press GmbH\&Co.
\end{tabular}

Bartels et al.: Cell Surface Association of Protein Disulfide Isomerases

- 71 Sharda A, Kim SH, Jasuja R, Gopal S, Flaumenhaft R, Furie BC, Furie B: Defective PDI release from platelets and endothelial cells impairs thrombus formation in Hermansky-Pudlak syndrome. Blood 2015;125:16331642.

- 72 Numata Y, Morimura T, Nakamura S, Hirano E, Kure S, Goto YI, Inoue K: Depletion of molecular chaperones from the endoplasmic reticulum and fragmentation of the Golgi apparatus associated with pathogenesis in Pelizaeus-Merzbacher disease. J Biol Chem 2013;288:7451-7466. 